\section{Evaluation of the Motherstalk Method of Asparagus (Asparagus officinalis L.) Production in a Greenhouse}

\author{
Stephen Reiners ${ }^{1}$ and Stephen A. Garrison ${ }^{2}$ \\ Department of Horticultural Sciences, 201 Hedrick Hall, New York State \\ Agricultural Experiment Station, Cornell University, Geneva, NY 14456-0462
}

Additional index words. harvesting, vegetative growth

\begin{abstract}
The motherstalk method of 'Jersey Centennial' asparagus production was examined in two greenhouse studies. This technique allowed for one, two, or three spears to develop a mature fern while permitting harvest of later-developing spears. Cumulative yield was highest 10 weeks after planting with one and two motherstalks, and crown dry weights in these treatments were similar to those of the nonharvested treatment. In a second experiment, spear yield and crown dry weight were determined when the motherstalk was initiated at $0,2.5$, and 5 weeks after planting. Yields were highest when the motherstalk was established at week 0 or 2.5 compared to week 5 . Crown dry weights of early motherstalk treatments were similar to those of the nonharvested treatment at the end of the 10-week harvest period. Our results indicate that the motherstalk system may allow for extended asparagus harvest in temperate areas.
\end{abstract}

Asparagus grown in temperate climates typically is harvested for 6 to 8 weeks each spring. This limited harvest season has led researchers to investigate ways to extend the cutting season (Sanders, 1985; Shelton and Lacy, 1980) or change harvest to summer (Takatori et al., 1970) or fall (Jasmin and Laliberte, 1962; Robb, 1986). In general, these attempts have failed due to the loss of crown storage carbohydrates necessary for the following-season's spear production (Takatori et al., 1970). Fern size and the time it is photosynthetically active determine the crown carbohydrate level (Shelton and Lacy, 1980). Harvest schedules that shorten the carbohydrate replenishment period result in decreased crown vigor and a corresponding stand loss.

The motherstalk method of asparagus production has proven successful in Taiwan and other tropical areas and allows for year-round spear production (Hung, 1980). With this method, the first three spears are allowed to develop a mature fern, but subsequent spears are harvested for an extended period. This fern or motherstalk then becomes the photosynthate source for the developing spears. Using the motherstalk method, Taiwan's cutting season and production per unit area are significantly greater than those of spring harvests in temperate climates. Robb (1986) has demonstrated the motherstalk system's potential for extending the harvest season of spring-grown asparagus in New Zealand. Our objectives

Received for publication 1 Nov. 1993. Accepted for publication 18 Apr. 1994. The cost of publishing this paper was defrayed in part by the payment of page charges. Under postal regulations, this paper therefore must be hereby marked advertisement solely to indicate this fact.

${ }^{1}$ Assistant Professor.

${ }^{2}$ Extension Specialist, Rutgers Research and Development Center, R.D. 5, Box 232, Bridgeton, NJ 08302 . were to determine the effects of the number of motherstalks (Expt. 1) and their time of emergence (Expt. 2) on the asparagus growth, yield, and dry matter accumulation in a model system under greenhouse conditions.
One-year-old 'Jersey Centennial' asparagus crowns were harvested from a southern New Jersey nursery. They were washed, graded, and refrigerated at $3 \mathrm{C}$. Crowns for the motherstalk count study, weighing between 60 and $80 \mathrm{~g}$, were removed from storage and further selected for uniformity of bud count and size within each replication. Crowns were planted in 3-liter plastic pots containing a steam-sterilized 1 soil : 1 sand (v/v) mix and limed to $\mathrm{pH}$ 6.5. The potted crowns were placed in a greenhouse on 20 May, with air temperatures ranging from 20 to $30 \mathrm{C}$. For Expt. 1, the treatments were 1) one motherstalk (1 MS); 2) two MS (2 MS); 3) three MS (3 MS); 4) no motherstalk, all spears harvested (0 MS); and 5) no harvest (FERN). The experimental unit consisted of eight crowns, replicated five times within a randomized complete-block design. Motherstalks, the first large spears to emerge after planting, were staked to avoid lodging. All 15-cm-tall spears that emerged after the motherstalk were harvested daily by cutting at the soil surface. Spear counts and weights were recorded and totaled on weekly. Five weeks after planting, half of the plants in each experimental unit were removed from their pots. Crowns were separated from ferns and gently washed to remove soil. Fresh and dry weights were recorded. The

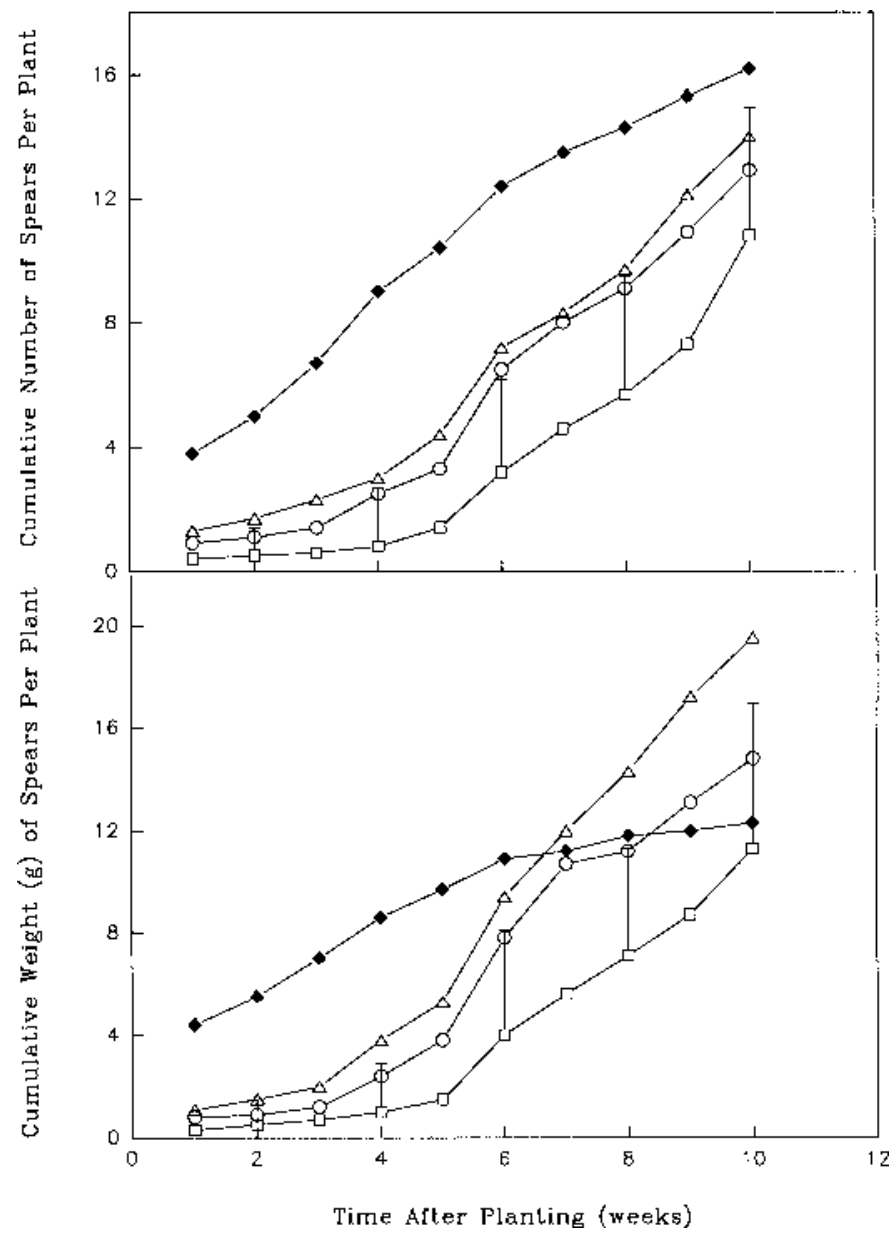

Fig. 1. The effect of motherstalk count on the cumulative number and weight of spears per plant. Treatments are 0 MS $(\bullet), 1$ MS $(\Delta), 2$ MS $(\bigcirc)$, and 3 MS ( $\square$ ). Vertical lines represent the HSD at $P \leq 0.05$. 
remaining plants were harvested after 10 weeks and subjected to the same analysis.

The effect of the time of motherstalk initiation on spear production was determined in Expt. 2. Crowns weighing between 40 and 60 $\mathrm{g}$ were removed from storage and grown under the same conditions in Expt. 1. The treatments were 1) start motherstalk from the beginning of the study (MSWk 0); 2) cut all spears and start motherstalk at 2.5 weeks after planting (MSWk 2.5); 3) cut all spears and start motherstalk at 5 weeks after planting (MSWk 5); 4) use no motherstalk, all spears harvested (0 MS); and 5) no harvest (FERN). All motherstalk treatments consisted of one stalk, and treatments differed only in the time of motherstalk establishment. The experimental unit, design, and data collection procedures were the same as described in Expt. 1. Data are expressed on a per plant basis and were subjected to an analysis of variance. Means were compared at $P \leq 0.05$ using the HSD procedure.

\section{Results and Discussion}

Number of motherstalks. In Expt. 1, 0 MS produced a significantly higher weight and number of spears than any other motherstalk treatment during the first 5 weeks of harvest (Fig. 1). Spear production with 1MS apparently was delayed by the developing fern, which agrees with Hung's (1980), and Kretschmer and Hartmann's (1979) work. A greater number of motherstalks increased the delay in spear production. Spear yield (weight) leveled off with $0 \mathrm{MS}$ after 6 weeks, but weights continued to increase in all other treatments. After 10 weeks of harvest, $1 \mathrm{MS}$ and 2 MS produced significantly higher cumulative spear weights than $0 \mathrm{MS}$. This result indicates that the average spear weights decreased in 0 MS, probably due to decreasing levels of crown storage carbohydrates (Lampert et al., 1980). Once established, the motherstalk may serve as a photosynthate source for developing spears (Downton and Torokfalvy, 1975; Hung, 1980).

At the end of 5 weeks, no significant differences existed in the crown dry weights among treatments (Table 1). After 10 weeks, however, 0 MS crowns weighed significantly less than those of any other treatment. The $1 \mathrm{MS}$ and $2 \mathrm{MS}$ plants had significantly higher crown dry weights and also produced significantly higher spear weights than did 0 MS after 10 weeks of harvest. No differences existed in the crown weights among any other treatments despite significantly greater fern production by FERN compared to the harvested MS treatments. This may be due to using crown reserves for the larger fern production. Extending this study past 10 weeks might have resulted in a larger crown for FERN, due to greater photosynthetic capacity. Scott et al. (1939) found that 3 months may be needed to replenish storage carbohydrates used in spear and fern production. Our Expt. 1 results indicate that one motherstalk is optimal for 1-yearold crowns weighing between 60 and $80 \mathrm{~g}$. For larger, more mature crowns with greater carbohydrate reserves, additional motherstalks may result in optimum yields.
Motherstalk timing. During the first 5 weeks of Expt. 2, all emerging spears for $0 \mathrm{MS}$ and MSWk 5 were harvested. As a result, plants of these treatments produced more spears and higher weights than MSWk 0 and MSWk 2.5 (Fig. 2). Yields increased for MSWk 0 and

Table 1. Effect of motherstalk number and timing on fern and crown dry weights at 5 and 10 weeks after planting. Data are means of eight plants in each of five replications.

\begin{tabular}{|c|c|c|c|c|}
\hline \multirow[b]{3}{*}{ Treatment } & \multicolumn{4}{|c|}{ Total dry wt (g) } \\
\hline & \multicolumn{2}{|c|}{5 weeks } & \multicolumn{2}{|c|}{10 weeks } \\
\hline & Fern & Crown & Fern & Crown \\
\hline \multicolumn{5}{|c|}{ Expt. 1} \\
\hline FERN & 5.9 & 9.3 & 16.3 & 24.6 \\
\hline $0 \mathrm{MS}$ & $--^{2}$ & 8.3 & $--^{2}$ & 10.3 \\
\hline $1 \mathrm{MS}$ & 3.9 & 10.9 & 6.8 & 26.2 \\
\hline $2 \mathrm{MS}$ & 4.1 & 11.2 & 6.9 & 22.9 \\
\hline $3 \mathrm{MS}$ & 6.2 & 10.4 & 12.9 & 23.0 \\
\hline HSD & 1.6 & NS & 6.2 & 10.5 \\
\hline \multicolumn{5}{|c|}{ Expt. 2} \\
\hline FERN & 7.4 & 8.2 & 16.4 & 25.5 \\
\hline $0 \mathrm{MS}$ & $--^{2}$ & 5.4 & $--^{2}$ & 3.5 \\
\hline MSWk 0 & 4.6 & 8.7 & 2.7 & 30.6 \\
\hline MSWk 2.5 & 3.1 & 5.7 & 2.6 & 20.6 \\
\hline MSWk 5 & $--^{2}$ & 5.7 & 0.6 & 9.6 \\
\hline HSD & 2.8 & NS & 1.7 & 10.5 \\
\hline
\end{tabular}

${ }^{2}$ No fern produced in these treatments.

Ns Nonsignificant according to HSD at $P \leq 0.05$.

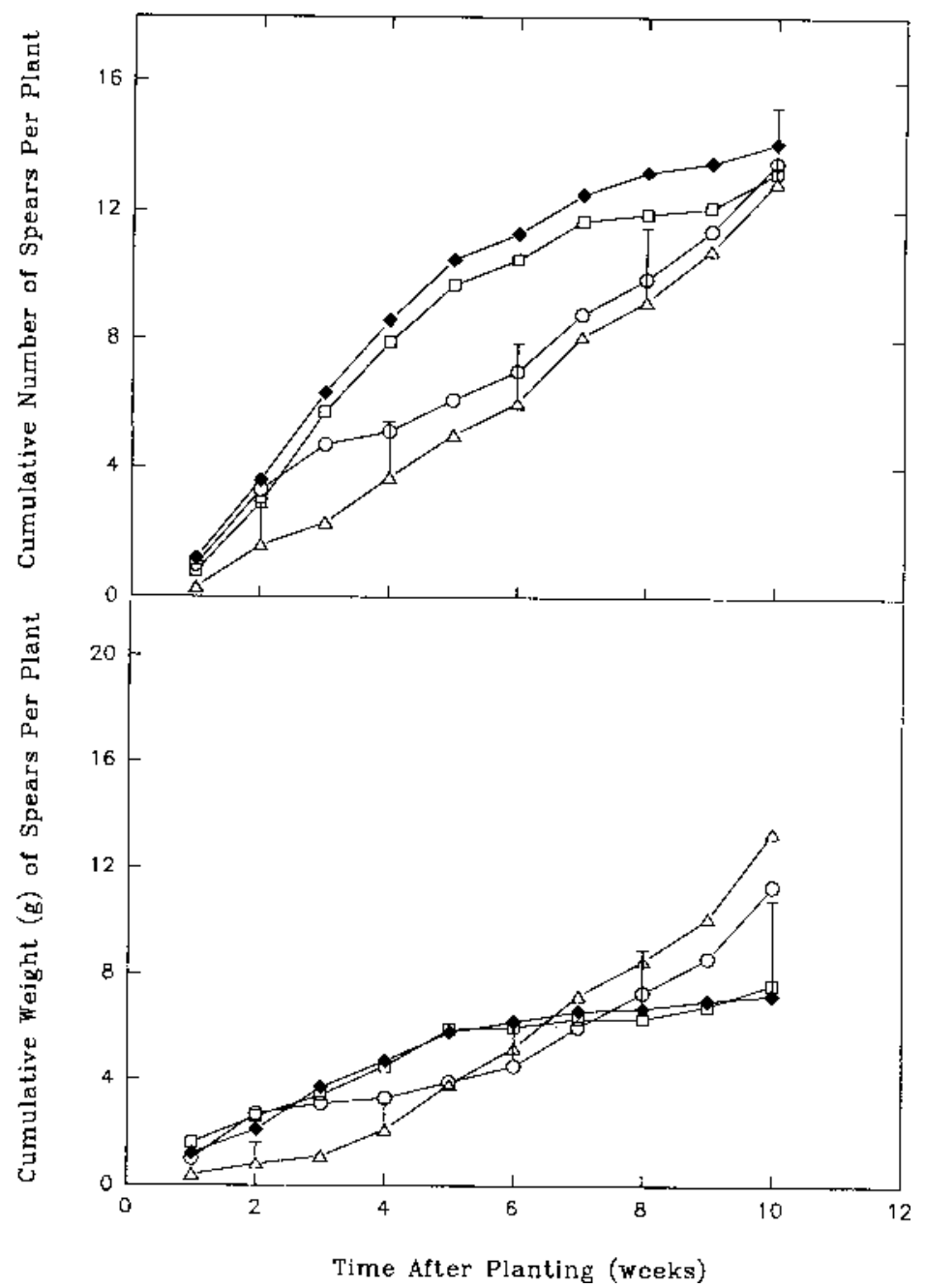

Fig. 2. The effect of motherstalk timing on the cumulative number and weight of spears per plant. Treatments are 0 MS $(\diamond)$, MSWk $0(\Delta)$, MSWk $2.5(\bigcirc)$, and MSWk $5.0(\square)$. Vertical lines represent the HSD at $P$ $\leq 0.05$. 
stress crowns of this size. By 5 weeks, crown dry weights declined to levels prohibiting production of a sizable fern (Table 1). As in Expt. 1 , MSWk 0 produced higher crown and spear dry weights than 0 MS after 10 weeks of harvest. At 10 weeks, the dry weight of the fern produced by MSWk 5 was one-fifth that for other MS treatments. Crown dry weights were similar for FERN, MSWk 0, and MSWk 2.5. It seems that crown storage carbohydrates reached a critical level between 2.5 and 5 weeks after spear emergence. Larger, more mature crowns may reach this level later in the season.

Under field conditions, the motherstalk method of asparagus production could extend the traditional temperate harvest season, currently limited to 6 to 10 weeks (Robb, 1986). Traditional harvesting could occur for 2 to 3 weeks. Then before crowns reach a critical dry weight level, the motherstalk(s) would be allowed to develop. After an initial decline in production as the motherstalk makes the tran- sition from a sink to a source of photosynthates, cutting could resume for an extended period. In these experiments, the production decline lasted 3 weeks from the time the motherstalk first emerged. Further work is necessary to evaluate this technique under field conditions in a temperate climate.

\section{Literature Cited}

Downton, W.J.S. and E. Torokfalvy. 1975. Photosynthesis in developing asparagus plants. Aust. J. Plant Physiol. 2:367-375.

Hung, L. 1980. Special aspects of growing asparagus in Taiwan. Chinese Soc. Hort. Sci. 26(1):110.

Jasmin, J.J. and J. Laliberte. 1962. Notes on fall cutting of asparagus on organic soils in southwestern Quebec. Can. J. Plant Sci. 42:737-738.

Kretschmer, M. and H.D. Hartmann. 1979. Experiments in apical dominance with Asparagus officinalis, p. 235-239. In: G. Reuther (ed.). Proc. 5th Intl. Asparagus Sym. Eucarpia, Geisenheim, Germany.

Lampert, E.P., D.J. Johnson, A.W. Tai, G. Kilpatrick,
R.H. Antosiak, P.H. Crowley, and E.D. Goodman. 1980. A computer simulation to maximize asparagus yields. J. Amer. Soc. Hort. Sci. 105(1):37-42.

Robb, A.R. 1986. Alternative harvesting strategies for New Zealand asparagus growers. Asparagus Res. Nwsl. 4:8-11.

Sanders, D.C. 1985. Influence of extended harvest duration on carbohydrate accumulation and yield of established asparagus, p. 333-337. In: E.C. Lougheed and H. Tiessen (eds.). Proc. 6th Intl. Asparagus Symp. Univ. of Guelph Press, Guelph, Ont., Canada.

Scott, L.E., J.H. Mitchell, and R.A. McGinty. 1939. Effects of certain treatments on the carbohydrate reserves of asparagus crowns. South Carolina Agr. Expt. Sta. Bul. 2321.

Shelton, D.R. and M.L. Lacy. 1980. Effect of harvest duration on yield and depletion of storage carbohydrates in asparagus roots. J. Amer. Soc. Hort. Sci. 105:332-335.

Takatori, F.H., J.J. Stillman, and F.D. Souther. 1970. Asparagus yields and plant vigor as influenced by time and duration of cutting. Calif. Agr. 24(4):8-10. 